\title{
Saddle Pulmonary Embolism in a Cancer Patient with Thrombocytopenia: A Treatment Dilemma
}

\author{
Ali Zalpour, ${ }^{1,2}$ Katy Hanzelka, ${ }^{1}$ John T. Patlan, ${ }^{2}$ \\ Marc A. Rozner, ${ }^{3}$ and Syed Wamique Yusuf ${ }^{4}$ \\ ${ }^{1}$ Division of Pharmacy, Pharmacy Clinical Programs, University of Texas MD Anderson Cancer Center, \\ 1400 Pressler Avenue, Unit 1465, FCT 13.5021, Houston, TX 77030, USA \\ ${ }^{2}$ Department of General Internal Medicine, Ambulatory Treatment Center, University of Texas MD Anderson Cancer Center, \\ 1400 Pressler Avenue, Unit 1465, FCT 13.5021, Houston, TX 77030, USA \\ ${ }^{3}$ Division of Anesthesiology and Critical Care, Departments of Anesthesiology and Perioperative Medicine and Cardiology, University \\ of Texas MD Anderson Cancer Center, 1400 Pressler Avenue, Unit 1465, FCT 13.5021, Houston, TX 77030, USA \\ ${ }^{4}$ Department of Cardiology, University of Texas MD Anderson Cancer Center, 1400 Pressler Avenue, Unit 1465, FCT 13.5021, Houston, \\ TX 77030, USA
}

Correspondence should be addressed to Ali Zalpour, azalpour@mdanderson.org and Syed Wamique Yusuf, syusuf@mdanderson.org

Received 29 September 2010; Accepted 8 December 2010

Academic Editor: Jean-Bernard Durand

Copyright ( 2011 Ali Zalpour et al. This is an open access article distributed under the Creative Commons Attribution License, which permits unrestricted use, distribution, and reproduction in any medium, provided the original work is properly cited.

The association between cancer and venous thromboembolism (VTE) is well established. Saddle pulmonary embolism is not uncommon in hospitalized cancer patients and confers a higher mortality. We report a case of saddle pulmonary embolism in a cancer patient with thrombocytopenia, discuss the bleeding risks, complexity of managing such patients and review current guidelines.

\section{Introduction}

Pulmonary embolism (PE) is common in hospitalized patients. Overall mortality for major pulmonary embolism is $22 \%$ and as high as $65 \%$ in those who require cardiopulmonary resuscitation [1]. Saddle pulmonary embolism in cancer patients carries a very poor prognosis, with mortality of $>80 \%$ at one year [2]. A number of patients with cancer and pulmonary embolism have concomitant thrombocytopenia, posing a great therapeutic challenge.

We report a case of saddle pulmonary embolism in a cancer patient with thrombocytopenia and discuss the bleeding risks, complexity of managing such patients and review current guidelines.

\section{Case Report}

A 73-year-old female with history of hepatocellular carcinoma due to long-standing hepatitis $\mathrm{C}$, presented to the emergency center with a sudden syncopal episode at home. Her past medical history was significant for portal hypertension, and variceal bleeding requiring blood transfusions. She was receiving sorafenib, which required dose reduction due to thrombocytopenia. Her platelets fluctuated between $46,000-113 \times 10^{9}$ during the treatment.

On examination she was stable with a blood pressure of $128 / 72 \mathrm{mmHg}$; heart rate of 80 beats per minute; respiratory rate of $22 /$ minute; temperature $36.7^{\circ} \mathrm{C}$; and $\mathrm{O}_{2}$ saturation of $96 \%$ on $2-3$ liters oxygen via nasal cannula. Heart sounds were normal with no signs of heart failure. 


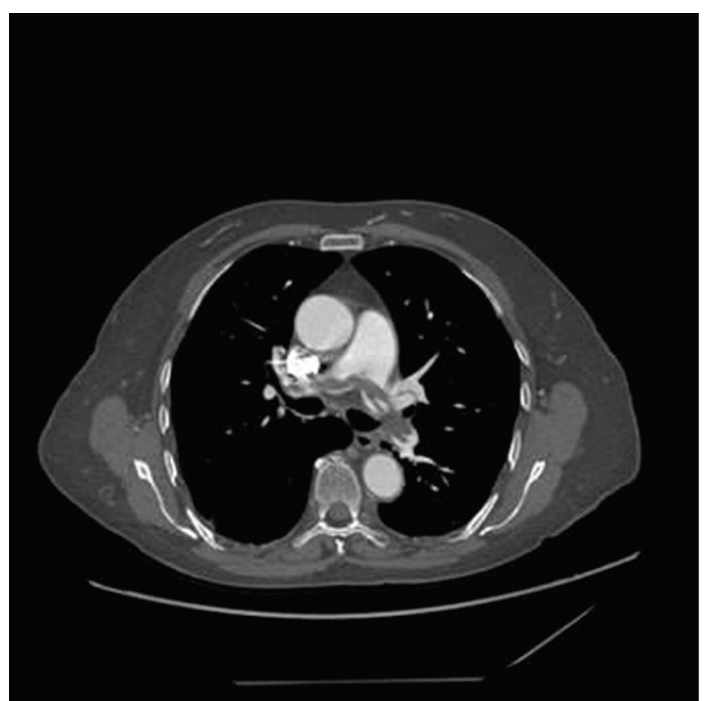

Figure 1: CT scan showing a saddle pulmonary embolus, extending into the right and left pulmonary arteries.

Relevant investigations included a 12 lead electrocardiogram (ECG), which showed sinus rhythm with left axis deviation, and no evidence of ischemia.

Serum troponin was marginally elevated at $0.12 \mathrm{ng} / \mathrm{mL}$ (Normal values: 0.00-0.03 ng/mL). Computerized (CT) scan of the lungs showed saddle $\mathrm{PE}$ with extension into the lobular braches (Figure 1). Chest X-ray was normal and venous Doppler study of the legs showed a partially attached right femoral thrombus. Platelet count was $60 \times 10^{9} / \mathrm{L}$ (Normal values: $\left.>150,000 \times 10^{9} / \mathrm{L}\right)$ and $\mathrm{D}$-dimer was $>20.00 \mathrm{mcg} / \mathrm{mL}$ (Normal values: $0.00-0.4 \mathrm{mcg} / \mathrm{mL}$ ). Hemoglobin, international normalized ratio (INR), activated partial thromboplastin time (aPTT), renal and liver function tests were within normal limits. Echocardiogram showed normal left and right ventricular (RV) systolic function with no pericardial effusion. Right ventricular systolic pressure was $29 \mathrm{mmHg}$.

She was treated with LMWH (Enoxaparin in a dose of $1 \mathrm{mg} / \mathrm{kg}$ subcutaneously twice daily) and inferior vena cava (IVC) filter was placed to prevent migration of the lower extremity thrombus. In view of her thrombocytopenia, hemodynamic stability and no evidence of RV dysfunction, she was not given thrombolytics. The patient's hemoglobin and platelets remained stable throughout the hospitalization and she was discharged home on LMWH.

\section{Discussion}

Venous thromboembolism (VTE) is common in cancer patients; with significant in hospital mortality $[1,3]$. In a large retrospective cohort study of hospitalized cancer patients, overall incidence of VTE was 4.1\% [4]. Cancer patients with VTE have higher in-hospital mortality compared to those who did not have VTE $(16.3 \%$ versus $6.3 \% ; P<.001)[4]$. In patients with $\mathrm{PE}$, comorbidities like older age ( $>70$ years), congestive heart failure, RV dysfunction and cancer increase the likelihood of mortality by at least 2-3-fold [3].

Cancer induces a prothrombotic state $[5,6]$. Malignant neoplasm alone is associated with a 4 -fold increased risk of VTE without chemotherapy, and cytotoxic immunosuppressive therapy increases the risk to more than 6-fold [7]. The most common chemotherapy agents associated with VTE are: thalidomide, lenalidomide with or without dexamethasone, L-asparginase, bevacizumab, tamoxifen, estramustine, capecitabine, erlotinib, sunitinib, vinorelbine, trastuzumab, paclitaxel-albumin-bound, letrozole, and bortezomib [8]. In addition to chemotherapy agents, central venous catheters (CVC) also act as predisposing factors. The incidence of venographic CVC-related DVT in cancer patients varies from $27 \%$ to $66 \%$ [9]. Risk of VTE also increases significantly in patients undergoing major surgical procedures for cancer [10].

Saddle pulmonary embolism in cancer patients carries a very poor prognosis, with mortality of $>80 \%$ at one year [2]. The treatment of saddle pulmonary embolism, particularly in the setting of concomitant thrombocytopenia, remains unclear and creates a great therapeutic challenge. The issue of treating thrombotic disease in cancer patients with thrombocytopenia secondary to myelosuppressive therapy has not been studied in large randomized clinical trials and therapy in these cases should be individualized based on risk benefit ratio.

3.1. Examining Guidelines for Treatment of PE. Treatment of saddle PE includes anticoagulants, thrombolytics and catheter based or surgical embolectomy [2]. In the absence of any large scale data, treatment should be individualized according to clinical status, evidence of RV dysfunction, cancer staging and risk of bleeding. Anticoagulants (heparin and warfarin) remain an integral part of all treatment plans.

3.2. Anticoagulants. National and international guidelines recommend LMWH as the first-line agent and Vitamin K antagonist (VKA) warfarin as a second line agent for the initial and long-term treatment of VTE in cancer patients [11-15] (Table 1). These recommendations are based on 4 clinical trials of VTE in cancer patients, comparing LMWH with warfarin from 3-6 months duration. Data beyond 6 months treatment with either LMWH or warfarin do not exist.

In a study of 146 cancer patients with VTE, in which enoxaparin $1.5 \mathrm{mg} / \mathrm{kg}$ was compared to warfarin (INR goal of 2-3), there were no significant differences at 3 months between the two treatment groups based on combined outcomes of recurrent VTE or major bleeding episodes (warfarin 21.1\%; (95\% confidence interval (CI), 12.3\%$32.4 \%$ ) versus enoxaparin $10.5 \%$; (95\% CI, 4.3\%-20.3\%); $(P=.09))$. This study enrolled only $47 \%$ cancer patient with DVT and PE without hemodynamic instability [16].

In another randomized trial of 676 cancer patients with VTE in which dalteparin in a dose adjusted protocol (200 IU/Kg daily for the first month and then $150 \mathrm{IU} / \mathrm{Kg}$ daily for the next 5 months) was compared to warfarin, there was 
TABLE 1: Summary of guidelines for treatment of VTE in cancer [11-15].

\begin{tabular}{|c|c|c|c|c|}
\hline Condition & ASCO & NCCN & AIOM/ESMO & ACCP \\
\hline $\begin{array}{l}\text { Initial treatment (acute } \\
\text { phase) }\end{array}$ & $\begin{array}{l}\text { - 5-10 days = LMWH } \\
\text { preferred }\end{array}$ & $\begin{array}{l}\text { - LMWH, UFH (IV), } \\
\text { FXa-I according to clinical } \\
\text { situation }\end{array}$ & $\begin{array}{l}\text { - LMWH, UFH (IV) } \\
\text { For CrCl less than } \\
\text { 25-30 mL/min, either } \\
\text { LMWH, UFH with antiXa } \\
\text { monitoring }\end{array}$ & $\begin{array}{l}\text { - LMWH or VKA for } \\
\text { minimum of } 90 \text { days }\end{array}$ \\
\hline $\begin{array}{l}\text { Long-term treatment } \\
\text { (chronic phase) }\end{array}$ & $\begin{array}{l}\text { - LMWH for } 180 \text { days } \\
\text { - If LMWH not available } \\
\text { then VKA } \\
\text { - indefinite in active } \\
\text { disease }\end{array}$ & $\begin{array}{l}\text { - LMWH preferred } \\
\text { - Indefinite in patients } \\
\text { with active and persistent } \\
\text { RF } \\
\text { - DVT for 3-6 months } \\
\text { - PE for 6-12 months }\end{array}$ & $\begin{array}{l}\text { - LMWH for 90-180 days } \\
\text { - Long-term for patients } \\
\text { with active cancer }\end{array}$ & $\begin{array}{l}\text { - LMWH or VKA for as } \\
\text { long as cancer active }\end{array}$ \\
\hline $\begin{array}{l}\text { Thrombolytic for initial } \\
\text { treatment }\end{array}$ & $\begin{array}{l}\text { Only in limb-threatening } \\
\text { thrombosis }\end{array}$ & $\begin{array}{l}\text { Massive DVT or PE with } \\
\text { hemodynamic instability }\end{array}$ & NA & NA \\
\hline IVCF & $\begin{array}{l}\text { - Presence of CI } \\
\text { - Recurrent VTE despite } \\
\text { AC }\end{array}$ & $\begin{array}{l}\text { - Presence of CI } \\
\text { - New PE that might be } \\
\text { life-threatening of PHTN }\end{array}$ & $\begin{array}{l}\text { - Presence of CI } \\
\text { - Recurrent PE despite } \\
\text { treatment }\end{array}$ & $\begin{array}{l}\text { - In patients with acute PE, } \\
\text { if anticoagulant is not } \\
\text { possible due to high-risk of } \\
\text { bleeding } \\
\text { - As soon as risk of bleeding } \\
\text { is minimal, AC should be } \\
\text { started }\end{array}$ \\
\hline
\end{tabular}

VTE: venous thromboembolism; ASCO: American Society of Clinical Oncology; NCCN: National Comprehensive Cancer Network; AIOM: Italian Association of Medical Oncology; ESMO: European Society of Medical Oncology; ACCP: American College of Chest Physician; LMWH:low-molecular-weightheparin; UFH: unfractionated heparin; FXa-I: factor- Xa inhibitor; VKA: vitamin K antagonist; RF: risk factors; DVT: deep-vein thrombosis; PE: pulmonary embolism; IVCF: inferior vena-caval filter; CI: contraindication; PHTN: pulmonary hypertension; AC: anticoagulation; IV: intravenous; NA: not addressed. CrCl: creatinine clearance.

a significant decrease in the cumulative risk of recurrent VTE in patients receiving dalteparin compared to warfarin $(8.3 \%$ versus $15.8 \%$; hazard ratio, $0.48 ; P=.002$ ). PE with or without DVT comprised only $30 \%$ of total enrolled patients [17].

In another trial of 91 cancer patients with VTE, in which 3 different regimens were compared: (1) enoxaparin $1.0 \mathrm{mg} / \mathrm{Kg}$ twice daily for 5 days followed by once daily $1.0 \mathrm{mg} / \mathrm{Kg}$ for 175 days; (2) enoxaparin $1.0 \mathrm{mg} / \mathrm{Kg}$ twice daily for 5 days then enoxaparin $1.5 \mathrm{mg} / \mathrm{Kg}$ once daily for 175 days; (3) enoxaparin $1.0 \mathrm{mg} / \mathrm{Kg}$ twice daily with warfarin for minimum of 5 days with an INR goal of 2-3; there were no significant differences between enoxaparin and warfarin in safety profile and recurrent VTE. In this study $45 \%$ of cancer patient with VTE had PE [18].

In a recent study of 200 cancer patients with VTE, in which tinzaparin in a dose of 175 International Factor Xa Inhibitory Units/Kg was compared to warfarin for an INR goal of 2-3, there was a significant decrease in cumulative risk of recurrent VTE at 10 months in patients assigned to tinzaparin $(P=.044)[19]$. In this trial, only $21 \%$ of patient had PE [19]. A recent meta-analysis showed superiority of LMWH over VKA in lowering rates of recurrent VTE in cancer patients [20]. Low-molecular-weight heparins (LMWHs) have become anticoagulants of choice due to their predictable pharmacokinetic and pharmacodynamic profiles. These agents are not therapeutically interchangeable due to their different molecular weight, half-life, and antiXa to IIa ratio [21]. LMWHs are considered intermediate acting anticoagulants with predictable kinetics. Specific pharmacokinetics of different anticoagulants, platelet monitoring, and recommendation for reversal in cases of bleeding are reviewed in Table 2. Monitoring of antiXa is recommended in obese patients, underweight patients, and patients with renal insufficiency, due to accumulation of LMWHs [22-27].

Warfarin is considered an alternative agent to LMWH. Due to major drug interactions between warfarin and chemotherapy, nutritional deficiency, and use of nonchemotherapy agents in cancer patients, frequent dose monitoring and modifications for warfarin is needed.

The difficulty in maintaining the narrow therapeutic index of warfarin also was shown in a major cancer trial where a therapeutic range INR (2-3) was achieved in only $46 \%$ of the patients [17]. Risk of VTE recurrence increases with subtherapeutic INR [30].

Direct factor-Xa inhibitor, fondaparinux, can also be considered for the initial (acute phase) treatment of PE. Fondaparinux was studied in a randomized clinical trial that showed noninferiority to unfractionated heparin in the acute treatment of PE; however, only $20 \%$ of patients enrolled in each arm had cancer. The incidence of VTE recurrence was $3.8 \%$ in the fondaparinux group and $5.0 \%$ in the unfractionated-heparin group, for an absolute difference in favor of fondaparinux of $1.2 \%$ (95\% confidence interval, -3.0 to 0.5$)$. The reported incidence of major bleeding was $2 \%$ in the fondaparinux group and $2.4 \%$ in the unfractionated heparin [33]. Due to lack of extended treatment trials, the role of fondaparinux for long-term treatment of VTE in cancer patients in unknown $[13-15,28]$.

Recently fixed-dose subcutaneous weight-adjusted unfractionated heparin (UFH) has also been recommended for the acute treatment of VTE [15]. The strength of this recommendation is weak and is based only on 2 studies, 
TABLe 2: Pharmacokinetics of different anticoagulants [22-29].

\begin{tabular}{|c|c|c|c|c|c|c|}
\hline Anticoagulant & $\begin{array}{l}\text { Molecular } \\
\text { weight }\end{array}$ & $\begin{array}{l}T^{1 / 2} \\
(\mathrm{~h})\end{array}$ & Elimination route & Antidote & Platelet monitoring & AntiXa monitoring \\
\hline $\begin{array}{l}\text { Enoxaparin } \\
\text { (lovenox) }\end{array}$ & $\begin{array}{l}3,500- \\
5,500\end{array}$ & $4.5-7$ & Renal & \multirow{3}{*}{$\begin{array}{l}\text { Protamine sulfate } 1 \mathrm{mg} \text { per } \\
100 \mathrm{U} \text { of heparin or less } \\
\text { than } 100 \text { mg over } 2 \text { hours } \\
\text { to lower risk of reaction. } \\
\text { Protamine partially reverses } \\
\text { the effect of LMWH } \\
\end{array}$} & $\begin{array}{l}\text { - Thrombocytopenia of any } \\
\text { degree should be } \\
\text { monitored closely } \\
\text { - Discontinue for platelet } \\
\text { count falls below } \\
100,000 / \mathrm{mm}^{3}\end{array}$ & $\begin{array}{l}-1 \mathrm{mg} / \mathrm{kg} \\
\mathrm{Q} 12=0.6-1.1 \mathrm{IU} / \mathrm{mL} \\
-1.5 \mathrm{mg} / \mathrm{kg} \\
\text { daily }=1.0-1.5 \mathrm{IU} / \mathrm{mL}\end{array}$ \\
\hline $\begin{array}{l}\text { Dalteparin } \\
\text { (fragmin) }\end{array}$ & $\begin{array}{l}5,600- \\
6,400\end{array}$ & $3-5$ & Renal & & $\begin{array}{l}\text { - For platelet counts } \\
\text { between } 50,000 \text { and } \\
100,000 / \mathrm{mm}^{3}, \text { reduce dose } \\
\text { of dalteparin by } 2,500 \mathrm{IU} \\
\text { until the platelet count } \\
\text { recovers to } \geq 100,000 / \mathrm{mm}^{3} \\
\text { - Discontinue for platelet } \\
\text { counts }<50,000 / \mathrm{mm}^{3}\end{array}$ & $\begin{array}{l}-100 \mathrm{IU} / \mathrm{kg} \\
\mathrm{Q} 12=0.4-1.1 \mathrm{IU} / \mathrm{mL} \\
-200 \mathrm{IU} / \mathrm{kg} \\
\text { daily }=1.0-2.0 \mathrm{IU} / \mathrm{mL}\end{array}$ \\
\hline $\begin{array}{l}\text { Tinzaparin } \\
\text { (innohep) }\end{array}$ & $\begin{array}{l}5,600- \\
7,500\end{array}$ & $3-4$ & Renal & & $\begin{array}{l}\text { - Thrombocytopenia of any } \\
\text { degree should be } \\
\text { monitored } \\
\text { - Discontinue for platelet } \\
\text { count below } 100,000 / \mathrm{mm}^{3}\end{array}$ & $\begin{array}{l}175 \mathrm{IU} / \mathrm{kg}=0.85- \\
1.0 \mathrm{IU} / \mathrm{mL}\end{array}$ \\
\hline $\begin{array}{l}\text { Unfractionated } \\
\text { heparin }\end{array}$ & $\begin{array}{l}5,000- \\
30,000\end{array}$ & $1-2$ & Renal/endothelial & $\begin{array}{l}\text { Protamine sulfate } 1 \mathrm{mg} \text { per } \\
100 \mathrm{U} \text { of heparin or less } \\
\text { than } 100 \mathrm{mg} \text { over } 2 \text { hours } \\
\text { to lower risk of reaction. }\end{array}$ & $\begin{array}{l}\text { - Thrombocytopenia of any } \\
\text { degree should be } \\
\text { monitored } \\
\text { - Discontinue for platelet } \\
\text { count below } 100,000 / \mathrm{mm}^{3} \\
\text { or if recurrent thrombosis } \\
\text { develops (sign and } \\
\text { symptoms of HIT) }\end{array}$ & aPTT monitoring \\
\hline $\begin{array}{l}\text { Fondaparinux } \\
\text { (arixtra) }\end{array}$ & $<2,500$ & $\begin{array}{l}17- \\
21\end{array}$ & Renal & $\begin{array}{l}\text { Recombinant factor VIIa } \\
90 \mathrm{mcg} / \mathrm{kg}\end{array}$ & $\begin{array}{l}\text { - Thrombocytopenia of any } \\
\text { degree should be } \\
\text { monitored } \\
\text { - Discontinue for platelet } \\
\text { count falls below } \\
100,000 / \mathrm{mm}^{3}\end{array}$ & $\begin{array}{l}-2.5 \mathrm{mg}=\text { peak at steady } \\
\text { state } 0.39-0.5 \mathrm{mg} / \mathrm{L} ; \\
\text { trough at steady state } \\
0.14-0.19 \mathrm{mg} / \mathrm{L} \\
-5 \mathrm{mg}, 7.5 \mathrm{mg} \text {, } \\
10 \mathrm{mg}=\text { peak at steady } \\
\text { state } 1.20-1.26 \mathrm{mg} / \mathrm{L} ; \\
\text { trough at steady state } \\
0.46-0.62 \mathrm{mg} / \mathrm{L}\end{array}$ \\
\hline
\end{tabular}

IV: intravenous; SC: subcutaneous; U: unit; UFH: unfractionated heparin; LMWH: low-molecular-weight heparin; $T^{1 / 2}$ : half-life elimination; HIT: heparininduced thrombocytopenia; aPTT: activated partial thromboplastin time.

each including only $22 \%$ patients with cancer with less than $20 \%$ patients with PE. Patients with hemodynamic compromise were excluded from these trials; therefore, PE patients with cardiovascular compromise should not receive UFH subcutaneously [15].

Recommended treatment duration of VTE in cancer patients is 6-12 months and indefinite in cases of metastatic or active cancer [11-15].

3.3. Thrombolytics. In the absence of contraindications, systemic thrombolytics should be considered in patients with massive PE and hemodynamic instability [11, 15]. The recommended dose of r-tPA is $100 \mathrm{mg}$ intravenously over 2 hours via peripheral vein [15].

However, cancer patients have been excluded from thrombolytic trials; hence evidence-based guidelines for the use of thrombolytics in this subset of population is lacking.
Except for a case report where streptokinase was used for the treatment of PE associated with heparin-induced thrombocytopenia [35], no other data exists on the use of thrombolytics in patients with PE and thrombocytopenia. Clinical judgment should be used and therapy individualized in each case.

3.4. Thrombectomy. Catheter and surgical thrombectomy are an option in selected patients. In a pregnant patient with $\mathrm{PE}$ and thromobcytopenia (due to myelodyplastic syndrome), successful emergency pulmonary embolectomy has been reported [36]. However, large-scale data in cancer patients is lacking [15].

3.5. IVC filter. Placement of IVC filter is recommended in patients with contraindication to anticoagulation, failure of 
TABLE 3: Multivariate analysis of the risk of developing fatal and major bleeding in cancer patients with venous thromboembolism (VTE) $[31,32]$.

\begin{tabular}{|c|c|c|c|c|c|}
\hline \multirow[b]{2}{*}{ Variables } & \multicolumn{2}{|c|}{ Fatal bleeding } & \multicolumn{3}{|c|}{ Major bleeding } \\
\hline & Odds ratio $(95 \% \mathrm{CI})$ & $P$-value & Variables & Odds ratio $(95 \% \mathrm{CI})$ & $P$-value \\
\hline Body weight $<60 \mathrm{~kg}$ & $2.5(1.1-5.3)$ & .021 & Recent major bleeding & $2.4(1.1-5.1)$ & .003 \\
\hline Recent major bleeding & $3.0(0.96-9.1)$ & .058 & $\mathrm{CrCl}<30 \mathrm{ml} / \mathrm{min}$ & $2.2(1.5-3.4)$ & $<.001$ \\
\hline $\begin{array}{l}\text { Serum creatinine } \\
>1.2 \mathrm{mg} / \mathrm{dL}\end{array}$ & $2.8(1.3-5.8)$ & .008 & Immobility for $\geq 4$ days & $1.8(1.2-2.7)$ & .005 \\
\hline Immobility for $\geq 4$ days & $4.1(1.9-8.7)$ & .001 & Metastatic cancer & $1.6(1.1-2.3)$ & .03 \\
\hline Metastatic cancer & $3.1(1.4-7.1)$ & .006 & & & \\
\hline
\end{tabular}

Confidence interval: CI; creatinine clearance: $\mathrm{CrCl}$.

TABLE 4: Multivariate analysis for major bleeding and bleeding risk index classification [34].

\begin{tabular}{llcc}
\hline Risk factors & Odds ratio $(95 \% \mathrm{CI})$ & $P$ & \multicolumn{1}{c}{ Points } \\
\hline Recent major bleed & $2.7(1.6-4.6)$ & $<.001$ & $<.001$ \\
Serum creatinine $>1.2 \mathrm{mg} / \mathrm{dL}$ & $2.1(1.7-2.8)$ & $<.001$ & 1.5 \\
Anemia & $2.1(1.7-2.7)$ & $<.001$ & 1.5 \\
Cancer & $1.7(1.4-2.2)$ & $<.001$ & 1 \\
Clinically overt pulmonary embolism & $1.7(1.4-2.2)$ & $<.001$ & 1 \\
Age $>75$ y & $1.7(1.3-2.1)$ & $>4$ points: high risk7.3\% $(95 \%$ CI: $4.0-9.1)$ \\
\hline 0 point: low risk $0.1 \%(95 \%$ CI: $0.0-0.2)$ & $\begin{array}{l}1-4 \text { points: intermediate risk } 2.8 \% \\
(95 \% \text { CI: } 2.4-3.3)\end{array}$ \\
\hline
\end{tabular}

anticoagulation, massive pulmonary embolism, severe cardiopulmonary disease with deep vein thrombosis, and free floating iliofemoral or inferior vena cava thrombus [11$15,37]$.

To date, there are no randomized clinical trials available in the cancer literature to assess the long-term safety and efficacy of filters. IVC filters carry short-term and long-term complications such as hematoma; misplacement, migration, thrombosis, recurrent PE, filter fracture, IVC occlusion and vena caval syndrome [38]. The insertion of an IVC filter does not obviate the need for long-term anticoagulation [15].

3.6. Assessing and Addressing Bleeding Risks. Prior to initiation of anticoagulation risk of bleeding should be assessed. Reported bleedings (major and minor combined) in cancer trials associated with VKA and LMWH are $3 \%-16 \%$ and $6 \%-11 \%$, respectively $[8,23]$. The Prospective registry, Registro Informatizado de La Enfermedad Thromboembólicà (RIETE), showed that patients with VTE and evidence of recent major bleed ( $<30$ days prior to diagnosis of VTE) had significantly higher rates of fatal bleeding $(4.1 \%$ versus $0.6 \% ; P<.001)$ and mortality $(9.5 \%$ versus $7.7 \% ; P<.005)$ compared to those without [39]. Multivariate analyses of RIETE showed that patients with a body weight of less than 60 kilograms, serum creatinine of $>1.2 \mathrm{mg} / \mathrm{dL}$, recent major bleeding, immobility for $>4$ days, clinically overt PE, and metastatic cancer had higher odds of developing fatal or major bleeding (Table 3) [31,32] When RIETE investigators cross-validated the predictive model into a validated group, after determination of point scores, the incidence of major bleeding was $0.1 \%$ (95\% CI: $0.0-0.2)$ in low-risk patients;
2.8\% (95\% CI: 2.4-3.3) in those at intermediate risk, and 6.2\% (95\% CI: 4.0-9.1) in high-risk patients. The incidence of major bleeding in the three groups was statistically different $(P<.001)$ (Table 4$)$ [34]. These prospective data have not measured the effect of thrombocytopenia into the bleeding risk scores. Advanced age, renal insufficiency, metastatic cancer, anemia, immobility, recent major bleeding, and clinically overt PE should prompt healthcare providers to closely monitor these patients for bleeding complications while receiving anticoagulation.

Transient thrombocytopenia due to myelosuppressive chemotherapy needs to be taken into consideration prior to initiation of anticoagulation as bleeding risks double from $10 \%$ at a platelet count of $20,000 / \mathrm{mm}^{3}$ to $20 \%$ when the platelet count drops to below $10,000 / \mathrm{mm}^{3}$ in solid tumor patients [40]. The timing and kinetics of platelet nadir is dependent on the mode of action, dose, and addition of multiple cytotoxic agents. Cytotoxic agents such as ifosfamide, carboplatin, etoposide, mesna, doxorubicin, and dacarbazine are associated with an early nadir. Delayed nadir can be seen in regimens containing nitrosoureas and melphalan. Novel agents such as lenalidomide and bortezomib can contribute to thrombocytopenia when added to other cytotoxic agents [40]. Enrolling cancer patients in VTE trials has been limited due to strict inclusion criteria; mainly to prevent bleeding complications. Cancer trials for VTE have excluded patients with platelet count as low as $30,000 / \mathrm{mm}^{3}$ to as high as $150,000 / \mathrm{mm}^{3}$ [16-19]. National Comprehensive Cancer Network (NCCN) considers platelet counts of less than $50,000 / \mathrm{mm}^{3}$ as a contraindication to prophylactic or therapeutic anticoagulation therapy [14]. American Society of Clinical Oncology (ASCO) recommends using therapeutic 
anticoagulation in cancer patients with preexisting thrombocytopenia with caution; therefore, close monitoring of platelets and hemoglobin is required in cancer patients [13]. Choosing an anticoagulant should be based upon the halflife, reversibility, tolerability, patient's preference, and cost [13]. Pharmacokinetic, pharmacodynamic, and monitoring parameters specific to each anticoagulants are discussed in Table 2. Briefly, unfractionated heparin provides a short half-life with complete reversibility by protamine sulfate; therefore, it is considered ideal agent for patients that may require rapid surgical interventions such as thrombectomy. LMWHs are considered intermediate to long-acting agents. Partial reversal of LMWHs in bleeding can be achieved by use of protamine sulfate. The half-life of fondaparinux is longer than LMWHs and partial reversibility can be achieved by administration of Recombinant factor VIIa (rVIIa) in bleeding episodes $[15,23]$. Vitamin $\mathrm{K}$ can be administered for reversal of bleeding associated with VKA. Fresh frozen plasma and cryoprecipitate can be administered in cases of life-threatening bleeding associated with anticoagulants [15]. In patients taking warfarin, Food and Drug Administration (FDA) has made recommendations regarding the potential benefits of genotype testing, to help reduce the bleeding risks in individual patients.

Risk of intracranial hemorrhage with thrombolytics in $\mathrm{PE}$ is about 3\% [3]. In a study of 104 patients with acute PE who received fibrinolytic therapy, $19 \%$ of patients experienced major bleeding. In this study, cancer, diabetes, and an elevated INR before initiation of fibrinolytic therapy were found to be an independent predictors of major bleeding [41].

The exact risk of bleeding in thrombocytopenic patients with PE is unknown. Platelet count less than $150,000 / \mathrm{mm}^{3}$ has been a predictor of short-term composite event such as mortality [42]. In clinical practice, platelet count of less than $50,000 \times 10^{9}$ is a contraindication to thrombolytic therapy [43].

No recommendations can be made regarding the use of thrombolytics in patients with thrombocytopenia and acute $\mathrm{PE}$, until large-scale data is available. Use of thrombolytic agents in cancer patients requires close attention to bleeding risks and overall prognosis.

\section{Conclusion}

There are several published guidelines for the treatment of VTE in cancer patients.

However, data on the management of saddle PE and particularly in patients with thrombocytopenia is lacking. Large-scale prospectively collected data and future studies are needed to address the best possible treatment option in these patients.

\section{Conflict of Interests}

The authors do not report any conflict of interests regarding this work.

\section{References}

[1] W. Kasper, S. Konstantinides, A. Geibel et al., "Management strategies and determinants of outcome in acute major pulmonary embolism: results of a multicenter registry," Journal of the American College of Cardiology, vol. 30, no. 5, pp. 1165$1173,1997$.

[2] S. W. Yusuf, G. Gladish, D. J. Lenihan et al., "Computerized tomographic finding of saddle pulmonary embolism is associated with high mortality in cancer patients," Internal Medicine Journal, vol. 40, no. 4, pp. 293-299, 2010.

[3] S. Z. Goldhaber, L. Visani, and M. De Rosa, "Acute pulmonary embolism: clinical outcomes in the International Cooperative Pulmonary Embolism Registry (ICOPER)," The Lancet, vol. 353, no. 9162, pp. 1386-1389, 1999.

[4] A. A. Khorana, C. W. Francis, E. Culakova, N. M. Kuderer, and G. H. Lyman, "Frequency, risk factors, and trends for venous thromboembolism among hospitalized cancer patients," Cancer, vol. 110, no. 10, pp. 2339-2346, 2007.

[5] G. Agnelli, "Venous thromboembolism and cancer: a two-way clinical association," Thrombosis and Haemostasis, vol. 78, no. 1, pp. 117-120, 1997.

[6] G. Y. H. Lip, B. S. P. Chin, and A. D. Blann, "Cancer and the prothrombotic state," Lancet Oncology, vol. 3, no. 1, pp. 27-34, 2002.

[7] J. A. Heit, M. D. Silverstein, D. N. Mohr, T. M. Petterson, W. M. O'Fallon, and L. J. Melton, "Risk factors for deep vein thrombosis and pulmonary embolism: a population-based case-control study," Archives of Internal Medicine, vol. 160, no. 6, pp. 809-815, 2000.

[8] B. Saraiya and S. Goodin, "Management of venous thromboembolism and the potential to impact overall survival in patients with cancer," Pharmacotherapy, vol. 29, no. 11, pp. 1344-1356, 2009.

[9] M. Verso and G. Agnelli, "Venous thromboembolism associated with long-term use of central venous catheters in cancer patients," Journal of Clinical Oncology, vol. 21, no. 19, pp. 3665-3675, 2003.

[10] D. Mukherjee, A. O. Lidor, K. M. Chu, S. L. Gearhart, E. R. Haut, and D. C. Chang, "Postoperative venous thromboembolism rates vary significantly after different types of major abdominal operations," Journal of Gastrointestinal Surgery, vol. 12, no. 11, pp. 2015-2022, 2008.

[11] A. A. Khorana, M. B. Streiff, D. Farge et al., "Venous thromboembolism prophylaxis and treatment in cancer: a consensus statement of major guidelines panels and call to action," Journal of Clinical Oncology, vol. 27, no. 29, pp. 49194926, 2009.

[12] M. Mandalà and R. Labianca, "Venous thromboembolism (VTE) in cancer patients. ESMO clinical recommendations for prevention and management," Thrombosis Research, vol. 125, supplement 2, pp. S117-S119, 2010.

[13] G. H. Lyman, A. A. Khorana, A. Falanga et al., "American Society of Clinical Oncology Guideline: recommendations for venous thromboembolism prophylaxis and treatment in patients with cancer," Journal of Clinical Oncology, vol. 25, no. 34, pp. 5490-5505, 2007.

[14] National Comprehensive Cancer Network Clinical Practice in Oncology, Venous thromboembolic disease. October 2010.

[15] C. Kearon, S. R. Kahn, G. Agnelli, S. Goldhaber, G. E. Raskob, and A. J. Comerota, "Antithrombotic therapy for venous thromboembolic disease: American College of Chest Physicians evidence-based clinical practice guidelines (8th edition)," Chest, vol. 133, no. 6, pp. 454-545, 2008. 
[16] G. Meyer, Z. Marjanovic, J. Valcke et al., "Comparison of low-molecular-weight heparin and warfarin for the secondary prevention of venous thromboembolism in patients with cancer: a randomized controlled study," Archives of Internal Medicine, vol. 162, no. 15, pp. 1729-1735, 2002.

[17] A. Y. Y. Lee, M. N. Levine, R. I. Baker et al., "Low-molecularweight heparin versus a coumarin for the prevention of recurrent venous thromboembolism in patients with cancer," The New England Journal of Medicine, vol. 349, no. 2, pp. 146153, 2003.

[18] S. R. Deitcher, C. M. Kessler, G. Merli, J. R. Rigas, R. M. Lyons, and J. Fareed, "Secondary prevention of venous thromboembolic events in patients with active cancer: enoxaparin alone versus initial enoxaparin followed by warfarin for a 180-day period," Clinical and Applied Thrombosis/Hemostasis, vol. 12, no. 4, pp. 389-396, 2006.

[19] R. D. Hull, G. F. Pineo, R. F. Brant et al., "Long-term low-molecular-weight heparin versus usual care in proximalvein thrombosis patients with cancer," American Journal of Medicine, vol. 119, no. 12, pp. 1062-1072, 2006.

[20] E. Aki, M. Barba, S. Rohilla et al., "Anticoagulation for the long term treatment of venous thromboembolism in patients with cancer," Cochrane Database of Systematic Reviews, no. 2, Article ID CD006650, 40 pages, 2008.

[21] P. Stratta, E. Karvela, C. Canavese et al., "Structure-activity relationships of low molecular weight heparins expose to the risk of achieving inappropriate targets in patients with renal failure," Current Medicinal Chemistry, vol. 16, no. 23, pp. 3028-3040, 2009.

[22] E. A. Nutescu, S. A. Spinler, A. Wittkowsky, and W. E. Dager, "Low-molecular-weight heparins in renal impairment and obesity: available evidence and clinical practice recommendations across medical and surgical settings," Annals of Pharmacotherapy, vol. 43, no. 6, pp. 1064-1083, 2009.

[23] M. A. Crowther and T. E. Warkentin, "Bleeding risk and the management of bleeding complications in patients undergoing anticoagulant therapy: focus on new anticoagulant agents," Blood, vol. 111, no. 10, pp. 4871-4879, 2008.

[24] Sanofi-Aventis Inc., Lovenox (Enoxaparin) Prescribing Information, Bridgewater, NJ, USA, 2009.

[25] Eisai Inc., Fragmin (Dalteparin) Prescribing Information, Woodcliff Lake, NJ, USA, 2007.

[26] LEO Pharma Inc., Innohep (Tinzaparin) Prescribing Information, Parsippany, NJ, USA, 2009.

[27] F. Michota and G. Merli, "Anticoagulation in special patient populations: are special dosing considerations required?" Cleveland Clinic Journal of Medicine, vol. 72, pp. S37-42, 2005.

[28] GlaxoSmithKline Inc., Arixtra (Fondaparinux) Prescribing Information, Research Triangle Park, NC, USA, 2010.

[29] Baxter Healthcare Corporation, Heparin Sodium Injection, Deerfield, Ill, USA, 2008.

[30] B. A. Hutten, M. H. Prins, M. Gent, J. Ginsberg, J. G. P. Tijssen, and H. R. Buller, "Incidence of recurrent thromboembolic and bleeding complications among patients with venous thromboembolism in relation to both malignancy and achieved international normalized ratio: a retrospective analysis," Journal of Clinical Oncology, vol. 18, no. 17, pp. 3078-3083, 2000.

[31] M. Monreal, C. Falgá, M. Valdés et al., "Fatal pulmonary embolism and fatal bleeding in cancer patients with venous thromboembolism: findings from the RIETE registry," Journal of Thrombosis and Haemostasis, vol. 4, no. 9, pp. 1950-1956, 2006.
[32] J. Trujillo-Santos, J. A. Nieto, G. Tiberio et al., "Predicting recurrences or major bleeding in cancer patients with venous thromboembolism: findings from the RIETE registry," Thrombosis and Haemostasis, vol. 100, no. 3, pp. 435-439, 2008.

[33] H. R. Büller, B. L. Davidson, H. Decousus et al., "Subcutaneous fondaparinux versus intravenous unfractionated heparin in the initial treatment of pulmonary embolism," The New England Journal of Medicine, vol. 349, no. 18, pp. 16951702, 2003.

[34] N. Ruíz-Giménez, C. Suárez, R. González et al., "Predictive variables for major bleeding events in patients presenting with documented acute venous thromboembolism. Findings from the RIETE Registry," Thrombosis and Haemostasis, vol. 100, no. 1, pp. 26-31, 2008.

[35] J. I. Cohen, M. R. Cooper, and C. S. Greenberg, "Streptokinase therapy of pulmonary emboli with heparin-associated thrombocytopenia," Archives of Internal Medicine, vol. 145, no. 9, pp. 1725-1726, 1985.

[36] S. Taniguchi, I. Fukuda, M. Minakawa, K. I. Watanabe, K. Daitoku, and Y. Suzuki, "Emergency pulmonary embolectomy during the second trimester of pregnancy: report of a case," Surgery Today, vol. 38, no. 1, pp. 59-61, 2008.

[37] "Practice guideline for the performance of percutaneous inferior vena cava (IVC) filter placement for the prevention of pulmonary embolism," September 2009, http://www.acr.org/.

[38] S. Ingber and W. H. Geerts, "Vena caval filters: current knowledge, uncertainties and practical approaches," Current Opinion in Hematology, vol. 16, no. 5, pp. 402-406, 2009.

[39] J. A. Nieto, A. D. De Tuesta, P. J. Marchena et al., "Clinical outcome of patients with venous thromboembolism and recent major bleeding: findings from a prospective registry (RIETE)," Journal of Thrombosis and Haemostasis, vol. 3, no. 4, pp. 703-709, 2005.

[40] S. Vadhan-Raj, "Management of chemotherapy-induced thrombocytopenia: current status of thrombopoietic agents," Seminars in Hematology, vol. 46, no. 2, pp. S26-S32, 2009.

[41] K. Fiumara, N. Kucher, J. Fanikos, and S. Z. Goldhaber, "Predictors of major hemorrhage following fibrinolysis for acute pulmonary embolism," American Journal of Cardiology, vol. 97, no. 1, pp. 127-129, 2006.

[42] J. F. Hsiao, C. M. Chu, C. M. Chung, S. T. Chang, C. T. Kuo, and J. T. Hsu, "Prognostic significance of thrombocytopenia in acute pulmonary embolism," Journal of Internal Medicine of Taiwan, vol. 19, no. 6, pp. 499-507, 2008.

[43] G. Piazza and S. Z. Goldhaber, "Management of submassive pulmonary embolism," Circulation, vol. 122, no. 11, pp. 1124$1129,2010$. 


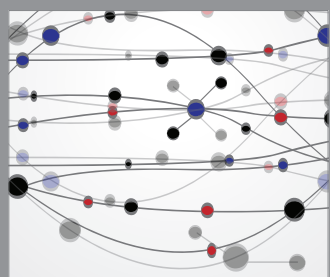

The Scientific World Journal
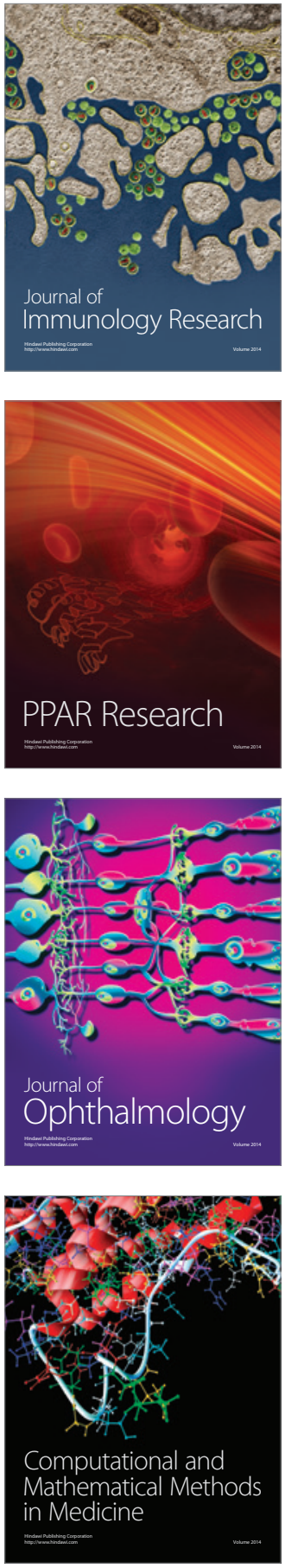

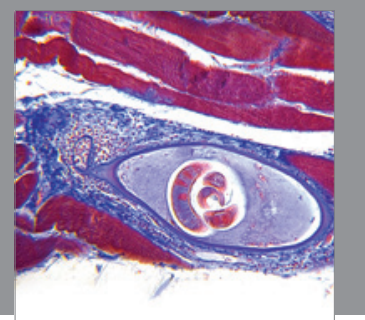

Gastroenterology

Research and Practice
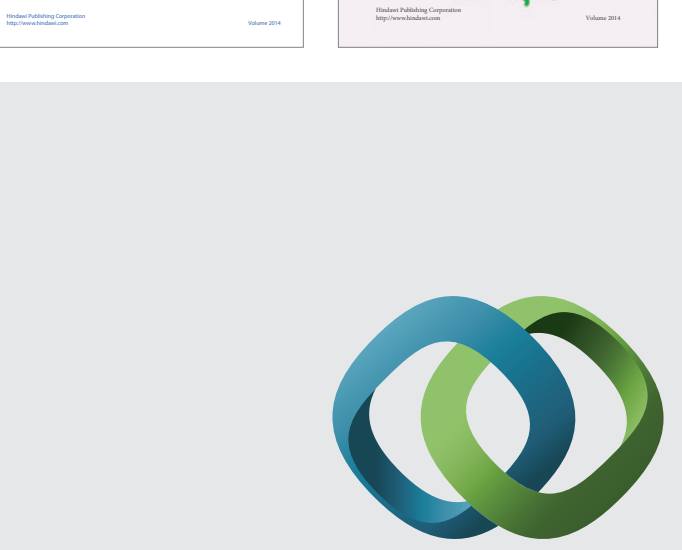

\section{Hindawi}

Submit your manuscripts at

http://www.hindawi.com
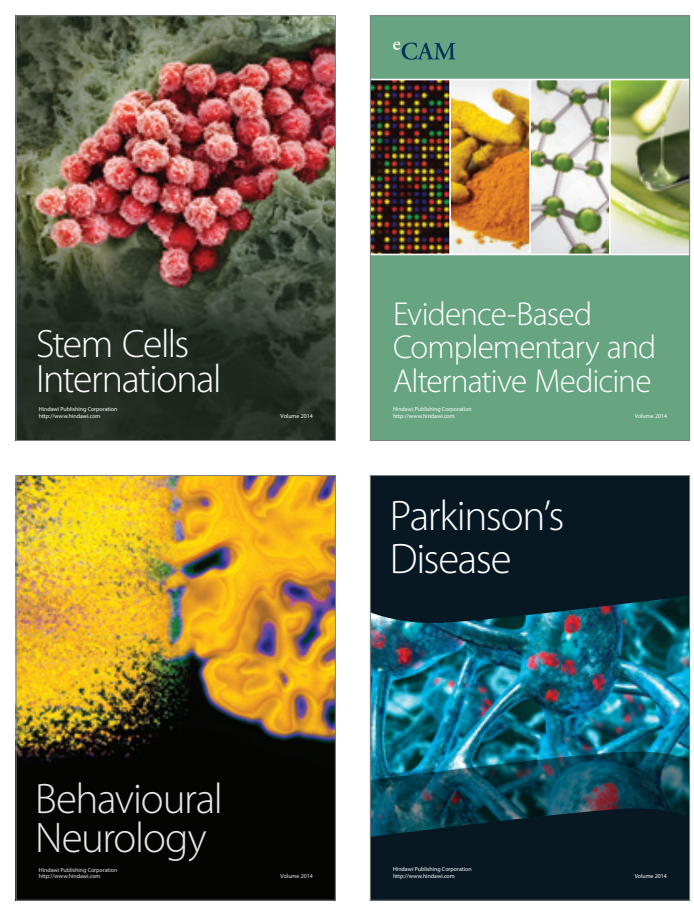

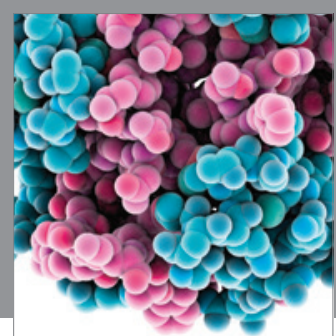

Journal of
Diabetes Research

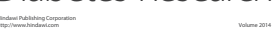

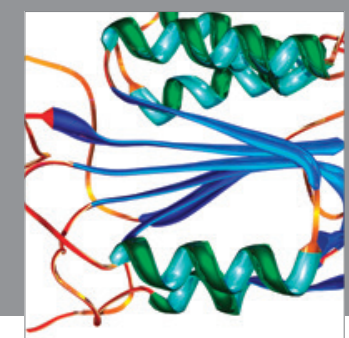

Disease Markers
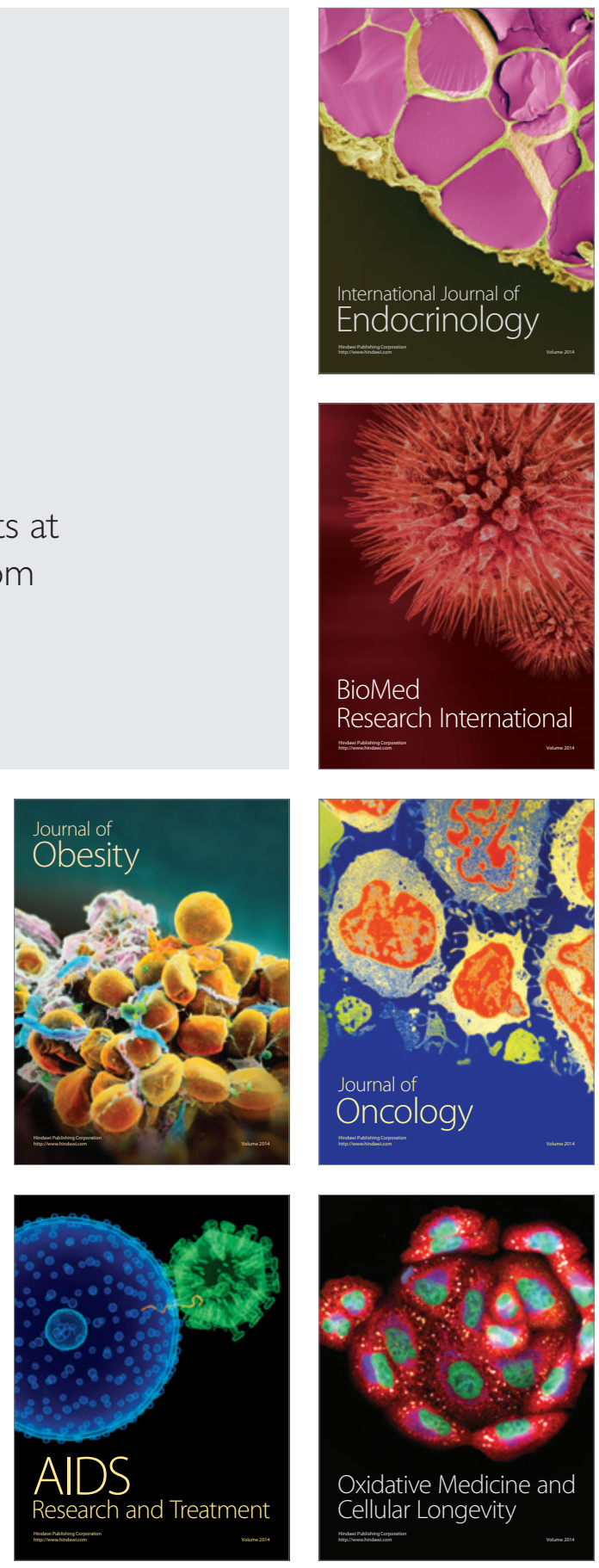